\title{
Research on Machine Tool Spindle System with Embedded FBG Temperature Sensors
}

\author{
https://doi.org/10.3991/ijoe.v13i01.6028 \\ Yanfang Dong*, Zude Zhou, Mingyao Liu \\ Wuhan University of Technology, Wuhan, China \\ xiaoqidong $104 @ 163 . \mathrm{com}$
}

\begin{abstract}
The spindle system is the core component of machine tool, And the spindle bearing temperature directly influences the size and direction of the spindle thermal error, as well as determines the machining surface quality. A complete spindle system including cutting force, bearing preload upload system, and precise description of bearing temperature field is beneficial to thermal error study and analysis of machining error. This paper set up a spindle system, which covers a preload upload system and a cutting force simulation system, and also a spindle bearing temperature measurement system. Besides, the bearing temperature fields were measured. Results show that optical fiber grating could be applied to the spindle bearing distribution temperature field measurement very well. It could play a certain role in promoting the development of intelligent spindle study.
\end{abstract}

Keywords - Spindle system, Bearing temperature measurement, Embedded FBG

\section{$1 \quad$ Introduction}

The spindle system has significant influences on the machine tool thermal error. The heat generated by the cutting force and bearing preload is the main heat source of the spindle system. Researching on the spindle thermal error has to construct a spindle system including cutting force simulation system and bearing preload upload system. And also the cutting force and bearing preload are the influence factors of bearing running conditions, the temperature rise and the uneven distributed temperature field especially.

Bearing temperature rise determines whether bearing is in an excellent running condition, affects the service life of bearings. In NC machine tool spindle system, the bearings are the main heat sources, whose high temperature directly affect the thermal deformation of machine tool structures, impact tools' offsets, and decide the size of thermal error. So it is necessary to monitor the rise of bearing temperature in real-time.

Uneven distribution of spindle bearing temperature, especially the local tem- 
perature rise of bearing[1], leads to a different expansion between the bearing inner ring and outer ring and changes the bearing radial clearance, thus enlarges the spindle vibration; inhomogeneous bearing temperature rise causes the spindle elongate and bend, influences the thermal error of machine tool further. Spindle bearing temperature rise is connected with tool cutting force, spindle speed and bearing preload force. The influencing factors are complicated to be analyzed. The traditional measuring method of spindle bearing temperature was single point measurement, which could not be engaged on the bearing outer ring temperature directly either, and data was less inaccurate. Sergei B.glavatskih et al.[2] used thermocouple to monitor sliding bearing temperature rise and it was far distance from measuring surface; Shuyun Jiang et al.[3] only used two thermocouples to measure bearing temperature, which was impossible to obtain the entire temperature data of the bearing; Chao Jin et al.[4] put sensors on screw instead of bearing. So it is also necessary to seek a better way to measure the distributed bearing temperature field.

Spindle bearings have small space for installing sensors, except the uneven temperature field distribution, its temperature also has problems that hard to predict and monitor in real-time. This research has been focused on for a long time and needs to make a big breakthrough urgently. Traditional temperature sensors, such as thermal resistance, etc., are vulnerable to electromagnetic interference and exits logging phenomenon, so those sensors are not beneficial to the distributed temperature measurement, and cannot meet the requirement of the spindle bearing temperature measurement. Lokesh A.Gupta used wireless temperature sensors to monitor the temperature field of bearing, but as the limited of the quality and volume of the sensors, some temperature measuring points cannot react to the change of the bearing state quickly [5].

Fiber Bragg grating(FBG), which is a new type of sensing components, has many advantages, such as high sensitivity, small volume, light weight, antielectromagnetic interference, high corrosion resistance and high temperature resistance, etc. [6,7]. Spindle bearing running environment exists a large amount of lubricating oil or grease and electromagnetic interference, but FBG can be suitable for this environment perfectly. The FBG center wavelength can be directly affected by some factors such as strain and temperature, and has a good linear response characteristic. It can be utilized for strain and temperature measurement, especially the temperature [8]. So it is the ideal measuring element in spindle bearing temperature measurement.

On the basis of the thorough understanding of factors which interfere with the bearing temperature, this paper set up a spindle system which has a cutting force simulation system, bearing preload upload system and FBG sensors embedded into the spindle bearing housing, completing the distributed temperature measurement of spindle bearing outer ring. 


\section{Related Works}

Fiber Bragg grating (FBG) can withstand both high temperature and low temperature. And FBG sensor arrays are easily made by connecting several Bragg gratings written at different center wavelengths in one line by using wavelength division multiplexing (WDM) technology, and the complicated wiring is avoided. That is why this paper selected FBG sensors. Fig.1 shows the structure and work principle of FBG.

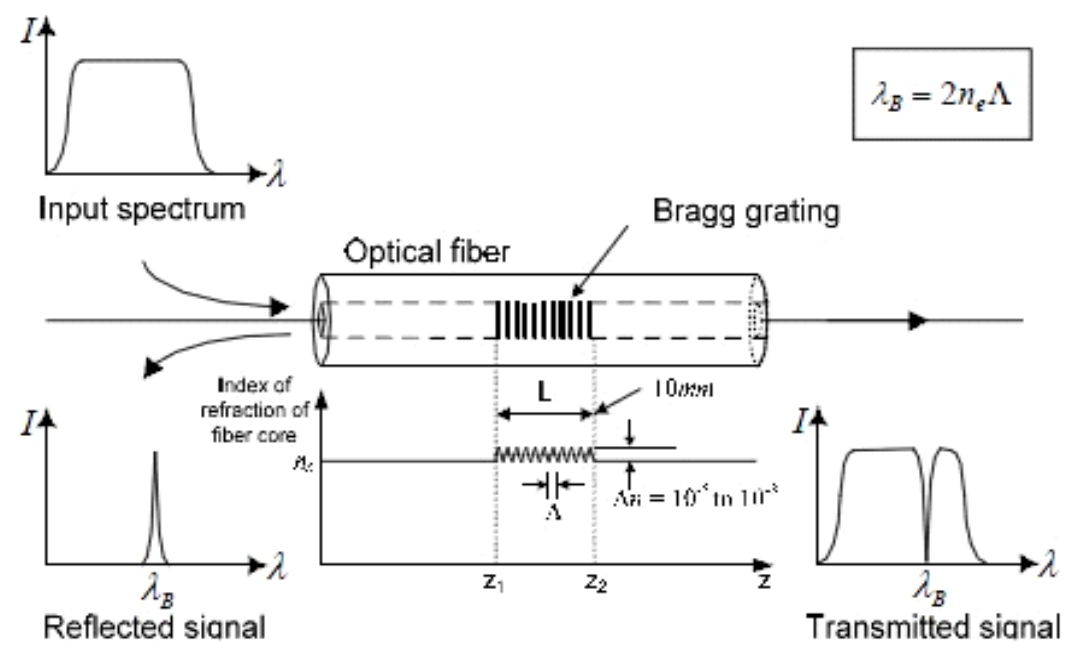

Fig. 1. Structure and work principle of FBG

For a change of temperature $\Delta T$, the corresponding center wavelength shift $\Delta \lambda_{B}$ is given by:

$$
\frac{\Delta \lambda_{B}}{\lambda_{B}}=\left(\xi_{f}+\alpha\right) \Delta T
$$

Where, $\xi \mathrm{f}$ is the thermal-optic coefficient. FBG temperature sensors have temperature sensitivity approximately about $10.0 \mathrm{pm} /{ }^{\circ} \mathrm{C}$, which is large enough for bearing temperature measurement.

As we know, bearing has different temperatures in circumferential direction when bears radial force especially. In order to describe the entire temperature field of bearing, this paper caught up with a bearing temperature field measurement method. The FBG sensors are distributed on the bearing outer ring, forming a ring of FBG sensors, as shown in Fig.2 and Fig.3. Taking full advantage of FBG WDM technology, the quantity of FBG sensors can be decided by the size of bearing. In this paper, we put six FBG sensors on the bearing outer ring. 


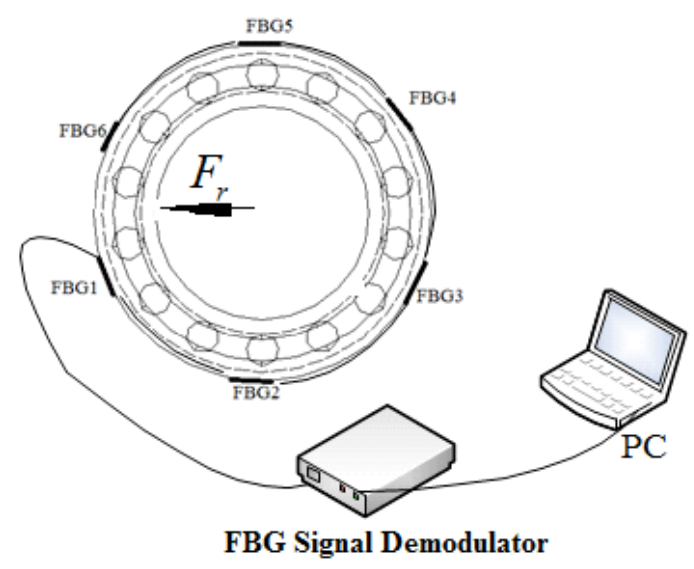

Fig. 2. Bearing temperature Measurement method

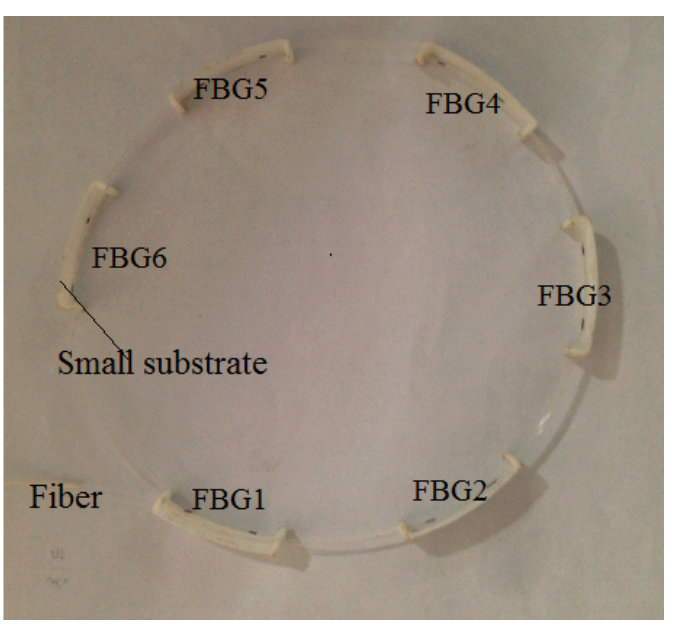

Fig. 3. Installed FBG sensors and the small substrates

And a ring groove is machined at a contact position between the bearing and the bearing block; FBG sensors lay in the ring groove. Small substrates are used to fix FBG sensors on the bearing slide ring groove; thermal conductive grease fills the gap. The heat transfers from thermal conductive grease to the FBG. The ring of FBG sensors can obtain the distribution temperature field which is impossible before.

After the installation of FBG sensors, because of the influence of thermal Grease and small substrates, the sensitivity of FBG will be affected by thermal expansion of the thermal grease and its own bending. Since FBG sensors are necessary to calibrate, this paper placed the whole bearing slider in constant temperature to calibrate the FBG sensors. The calibration results of one FBG sensor is shown in Fig.4; all calibration results of FBG sensors are shown in Table 1. 
Table 1. All calibration results of FBG sensors

\begin{tabular}{|c|c|c|c|c|c|c|}
\hline & FBG1 & FBG2 & FBG3 & FBG4 & FBG5 & FBG6 \\
\hline Slope & 0.010 & 0.011 & 0.010 & 0.010 & 0.010 & 0.011 \\
\hline Intercept & 1537.8 & 1541.858 & 1544.87 & 1549.86 & 1554.87 & 1558.89 \\
\hline Deviation & $5 \mathrm{E}-4$ & $1.4 \mathrm{E}-4$ & $1.66 \mathrm{E}-4$ & $1.69 \mathrm{E}-4$ & $1.86 \mathrm{E}-4$ & $1.32 \mathrm{E}-4$ \\
\hline
\end{tabular}

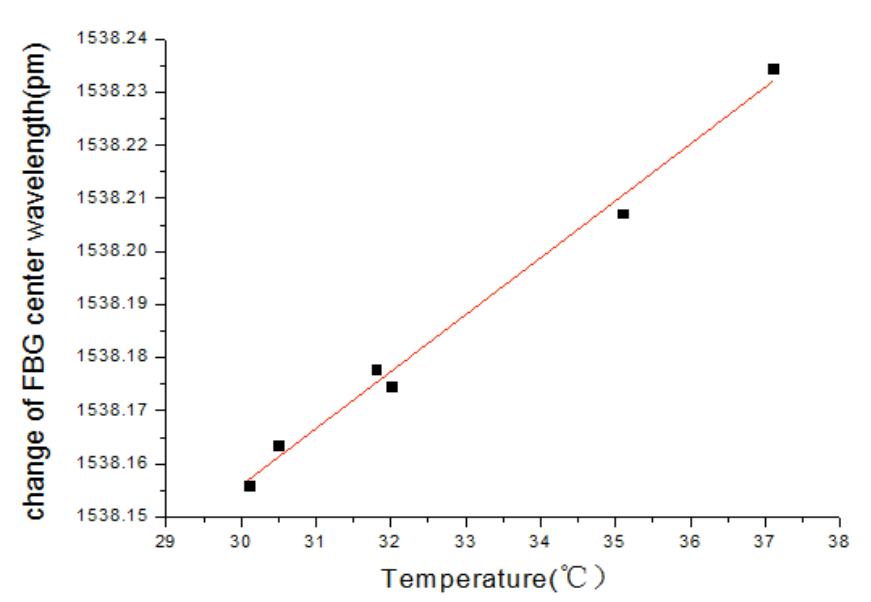

Fig. 4. FBG1 calibration curve

\section{System Descriptions}

Bearing types and configuration forms in NC machine tool spindle are varied, such as angular contact ball bearing or cylindrical roller bearing and the back-toback or the face-to-face bearing configuration form. This article mainly studied about the angular contact ball bearing spindle system which is the most commonly used at the present stage.

In this paper, the spindle system can realize the bearing preload force uploading, cutting force simulation and speed adjustment. The spindle system structures are shown in Fig.5, including: elastic coupling, servo driver, bearing slider and housing. This whole measurement system is installed on vibration isolation platform.

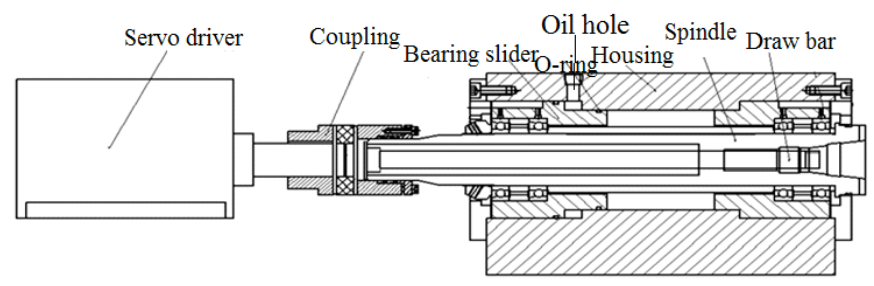

Fig. 5. Sectional view of the spindle system 
This paper builds a cutting force simulation device as shown in Fig.6, including the adjustment of the axial force and radial force. Spindle taper is connected with spindle. The function of the sliders (NO. one, two and three) is to fix force sensors and reduce changes of the display value caused by vibration, and the sliders move along the linear guide rails. Hand-wheels are used to adjust screw to alter axial force and radial force.

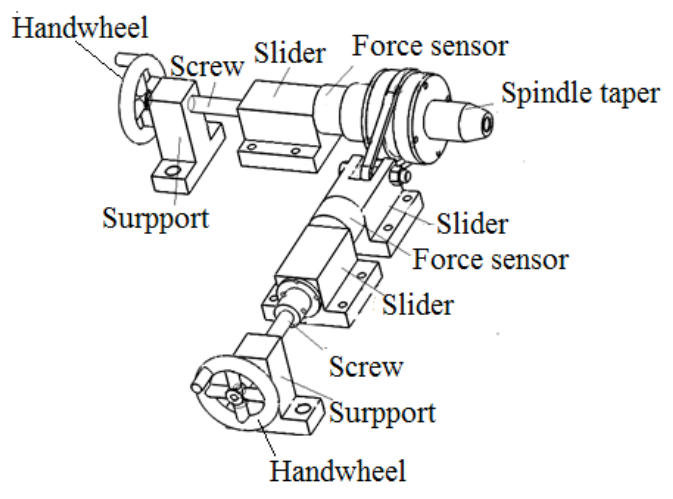

Fig. 6. Cutting force simulation device

Optimum preload can control the bearing temperature rise. The spindle system set up in this paper include the bearing preload upload device, shown in Fig.7.

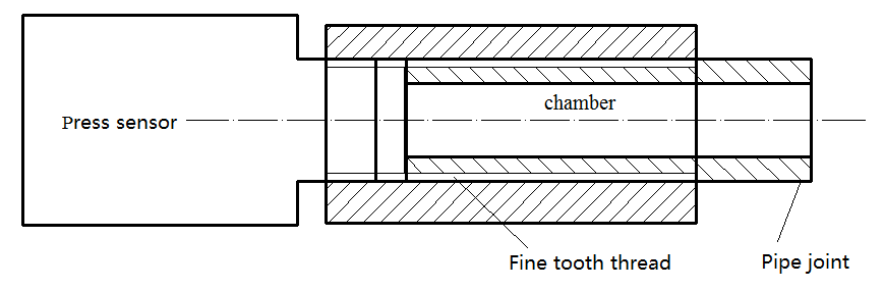

Fig. 7. Bearing preload upload device

The press sensor used to measure the oil pressure; the movement of fine tooth thread reduces the chamber and controls the pressure of the chamber; and the pipe joint connects the oil hole on the spindle housing, shown in Fig.5.

The distribution of spindle bearing temperature field is mainly influenced by cutting force, bearing preload and rotating speed, which were contained in the spindle system. The spindle system is shown in Fig.8. And the spindle bearing temperature measuring system set up in this paper using the embedded FBG temperature sensors can accomplish the accurate temperature rise measurement and description of bearing temperature field under different conditions of spindle speed, axial force, radial force and bearing preload. 


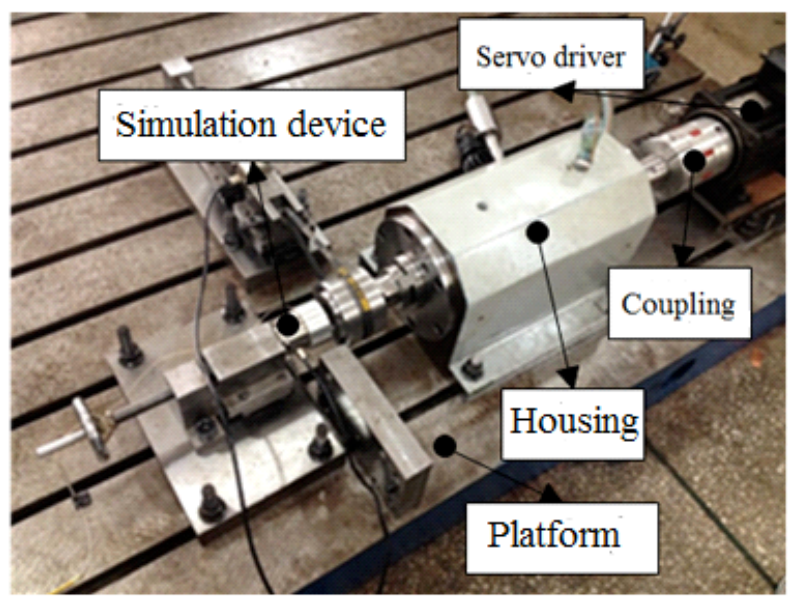

Fig. 8. The spindle system

\section{Experiments Performance}

Increasing the spindle rotation speed and feed rate is a method to enhance the efficiency of machining. Along with the continuous increase of those values, higher requirements to the spindle bearing are required. In particular, the development of motor spindle makes the spindle speed elevated to a new height. A big feed rate and increase of speed are a huge burden to bearings. Aiming at measuring the bearing temperature fields under the two main factors mentioned above, this paper carried out experiments on the measurement bearing temperature rise under situations of different spindle speeds, different cutting forces and different bearing preloads. Specific results are shown in Fig.9, Fig. 10 and Fig.11.

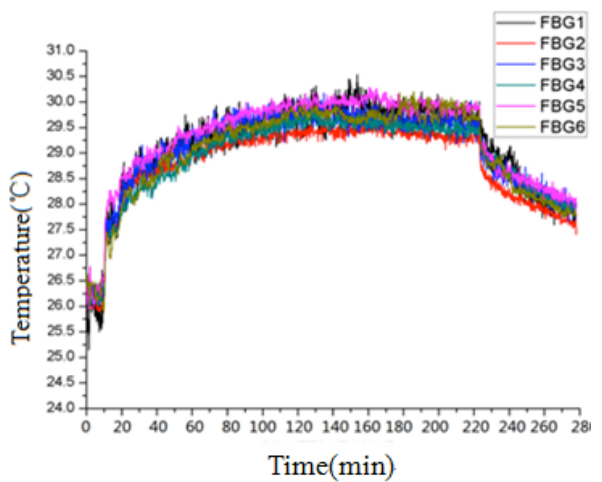

(a)

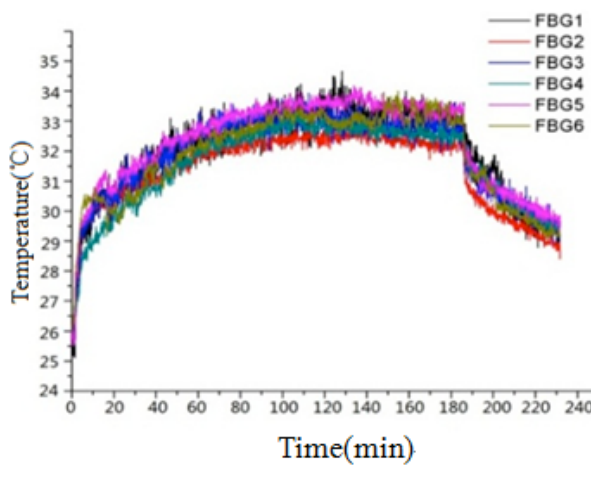

(b)

Fig. 9. Spindle bearing temperature rise curves at each measuring point $(\mathrm{a}: 800 \mathrm{r} / \mathrm{min}, \mathrm{b}: 2000 \mathrm{r} / \mathrm{min})$ 


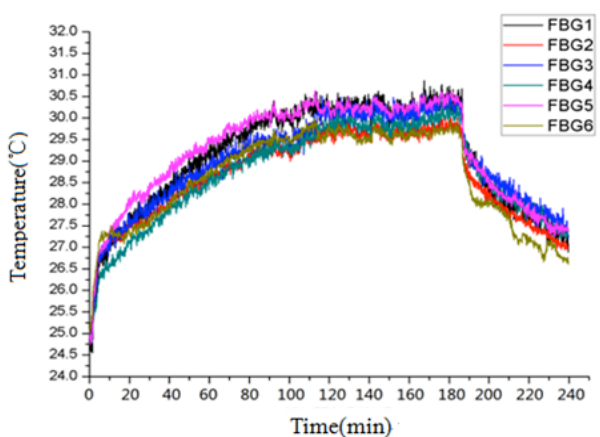

(a)

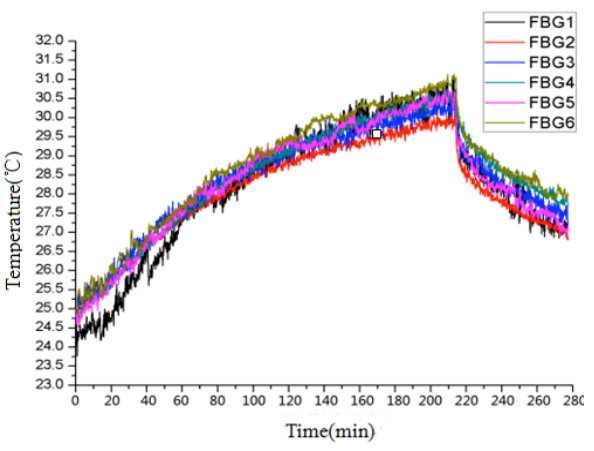

(b)

Fig. 10.Spindle bearing temperature rise curves at each measuring point under different axial force and $800 \mathrm{r} / \mathrm{min}$ spindle speed (a:1000N, b: 2000N)

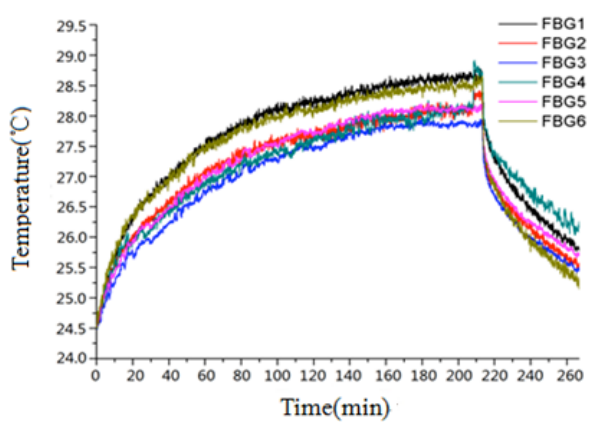

(a)

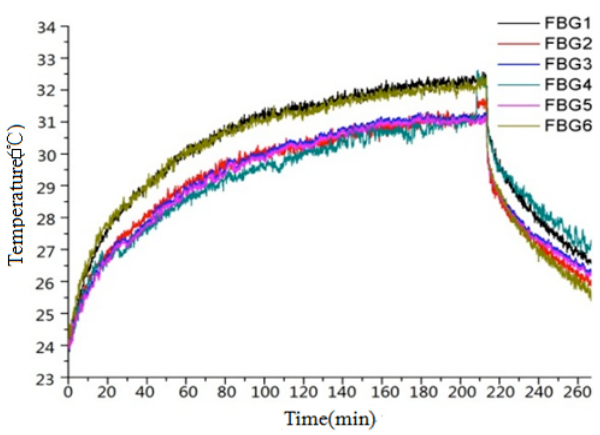

(b)

Fig. 11.Spindle bearing temperature rise curves at each measuring point under different radial force and $800 \mathrm{r} / \mathrm{min}$ spindle speed (a: $500 \mathrm{~N}, \mathrm{~b}: 1000 \mathrm{~N}$ )

This paper completed the measurement of spindle bearing temperature rise at the condition of the $800 \mathrm{r} / \mathrm{min}, 2000 \mathrm{r} / \mathrm{min}$; of the $800 \mathrm{r} / \mathrm{min}$, axial force $1000 \mathrm{~N}$ and $2000 \mathrm{~N}$; of the $800 \mathrm{r} / \mathrm{min}$, radial force under $500 \mathrm{~N}$ and $1000 \mathrm{~N}$. Fig. 7 shows that the FBG sensors have a uniform temperature rise, and the bearing temperature rise of the spindle has a $2000 \mathrm{r} / \mathrm{min}$ exceeds the rise of the spindle has a $800 \mathrm{r} / \mathrm{min}$ speed at the condition of thermal equilibrium; Fig. 8 shows that the FBG sensors also have a uniform temperature rise, and the bearing temperature rise of the spindle has a $2000 \mathrm{~N}$ axial force exceeds the rise of the spindle has a $1000 \mathrm{~N}$ axial force at the condition of thermal equilibrium; From Fig.7 and Fig.8, the temperature rise of spindle bearing under idle operation and axial force curves show a similar trend, which indicates that axial force were applied on each rolling element evenly, and this was consistent with the bearing force analysis.Fig.9 shows when the spindle radial force, the bearing has local temperature rise, there is a $1^{\circ} \mathrm{C}$ temperature difference when the spindle under a $500 \mathrm{~N}$ radial force and $2^{\circ} \mathrm{C}$ temperature difference when spindle under a $1000 \mathrm{~N}$ radial force; From Fig.7 and Fig.9, spindle bearing under different radial forces, the temperature of FBG1 and FBG6 is higher than other FBG sensors, also in accordance with bearing force analysis [9]. 


\section{Conclusions}

This paper set up a spindle system, including a cutting force simulation system, bearing preload upload device and speed adjustment, also combined with the unique advantages of FBG, designed a spindle system, a bearing temperature field measurement system, measured the temperature field of the bearing. The main research work and conclusions were summarized as follows:

1. A bearing temperature field measurement system based on FBG sensors was designed, including: a spindle system, a bearing preload uploading system and a cutting force simulation system.

2. The measurement experiment results showed the bearing temperature is uniform when bearing under idle condition and axial force, but non uniform when bearing under radial force which is in accordance with bearing force analysis.

This paper verified the fact that FBG can effectively be applied to the bearing temperature field measurement.

\section{$6 \quad$ References}

1. Liu Mingyao, et al. Measurement of Temperature Field for the Spindle of Machine Tool Based on Optical Fiber Bragg Grating Sensors[J]. Advances in Mechanical Engineering, 5(2013): 940626-940626. https://doi.org/10.1155/2013/940626

2. Sergei B. Glavatskih,sten Uusitalo, Daniel J. Spohn. Simultaneous monitoring of oil film thickness and temperature in fluid film bearings[J]. Tribology International, 34 (2001): 853-857. https://doi.org/10.1016/S0301-679X(01)00086-X

3. Shuyun Jiang, Hebing Mao. Investigation of variable optimum preload for a machine tool spindle[J]. International Journal of Machine Tools \& Manufacture, 50 (2010) :19-28. https://doi.org/10.1016/j.ijmachtools.2009.10.001

4. Chao Jin, Bo Wu, Youmin Hu. Heat generation modeling of ball bearing based on internal load distribution[J]. Tribology International, 45 (2012): 8-15. https://doi.org/10.1016/j.trib oint.2011.08.019

5. Lokesh A. Gupta, Dimitrios Peroulis. Wireless Temperature Sensor for Condition Monitoring of Bearings Operating Trough Tick Metal Plates[J]. IEEE Sensors Journal,6(2013):2292-2298. https://doi.org/10.1109/JSEN.2013.2251970

6. ZHOU Zude et al. Actualities and Development on Dynamic Monitoring and Diagnosis with Distributed Fiber Bragg Grating in Mechanical System [J]. Journal of Mechanical Engineering, 49(2013): 55-69. https://doi.org/10.3901/JME.2013.19.055

7. A. D. Kersey, M. A. Davis, H. J. Patrick et al. Fiber grating sensors[J]. Journal of Lightwave Technology, 15(1997):1442-1463. https://doi.org/10.1109/50.618377

8. Yi Liu, et al. Measurement error of surface-mounted fiber Bragg grating temperature sensor [J]. Review of Scientific Instruments, 85(2014):064905. https://doi.org/10.1063/1.488 $\underline{5463}$

9. Patrick Marconnet, et al. Measuring load distribution on the outer raceways of rotating machines[J]. Mechanical Systems and Signal Processing, 2015-66. 


\section{$7 \quad$ Authors}

Yanfang DONG (corresponding author) is with the School of Mechanical and Electronic Engineering, Wuhan University of Technology, Wuhan 430070, China. E-mail: xiaoqidong104@163.com.

Zude ZHOU is with the School of Mechanical and Electronic Engineering Wuhan University of Technology, Wuhan 430070, China.

Mingyao LIU is with the School of Mechanical and Electronic Engineering, Wuhan University of Technology, Wuhan 430070, China.

This research is supported by Hubei Digital Manufacturing Key Laboratory and National Natural Science Foundation (NO: 51475343). Submitted 11 July 2016. Published as resubmitted by the authors 18 August 2016. 